\title{
Convergence of a General Composite Iterative Method for a Countable Family of Nonexpansive Mappings
}

\author{
Shuang Wang \\ School of Mathematical Sciences, Yancheng Teachers University, Yancheng, 224051 Jiangsu, China \\ Correspondence should be addressed to Shuang Wang, wangshuang19841119@163.com \\ Received 17 March 2012; Accepted 10 May 2012 \\ Academic Editors: A. Bellouquid, E. Kita, and J. Nedoma \\ Copyright (C) 2012 Shuang Wang. This is an open access article distributed under the Creative \\ Commons Attribution License, which permits unrestricted use, distribution, and reproduction in \\ any medium, provided the original work is properly cited. \\ We propose a general composite iterative method for computing common fixed points of a \\ countable family of nonexpansive mappings in the framework of Hilbert spaces. Our results \\ improve and complement the corresponding ones announced by many others.
}

\section{Introduction and Main Result}

Let $H$ be a real Hilbert space with inner product $\langle\cdot, \cdot\rangle$ and norm $\|\cdot\|$. A mapping $T: H \rightarrow H$ is said to be nonexpansive if $\|T x-T y\| \leq\|x-y\|$ for all $x, y \in H$. The set of fixed points, $\operatorname{Fix}(T)=\{x \in H: T x=x\}$, of a nonexpansive mapping is always a closed and convex subset of $H$.

In addition to nonexpansive mappings, we are going to use contractions and $k$ Lipschitzian and $\eta$-strongly monotone operators. A self-mapping $f: H \rightarrow H$ is a contraction on $H$, if there exists a constant $\alpha \in(0,1)$ such that $\|f(x)-f(y)\| \leq \alpha\|x-y\|$, for all $x, y \in H$. We use $\Pi_{H}$ to denote the collection of mappings $f$ verifying the above inequality. That is, $\Pi_{H}=\{f: H \rightarrow H \mid f$ is a contraction with constant $\alpha\}$. A mapping $F: H \rightarrow H$ is called $k$-Lipschitzian if there exists a positive constant $k$ such that

$$
\|F x-F y\| \leq k\|x-y\|, \quad \forall x, y \in H .
$$

$F$ is said to be $\eta$-strongly monotone if there exists a positive constant $\eta$ such that

$$
\langle F x-F y, x-y\rangle \geq \eta\|x-y\|^{2}, \quad \forall x, y \in H .
$$


Recently, Jung [1] introduced the following composite iterative scheme for the solution of a specific minimization problem, which involves a closed convex subset $C \subseteq H$, a nonexpansive mapping $T: C \rightarrow C$, and a contraction $f: C \rightarrow C$,

$$
\begin{gathered}
x_{1}=x \in C \text { arbitrarily chosen, } \\
y_{n}=\alpha_{n} f\left(x_{n}\right)+\left(1-\alpha_{n}\right) T x_{n}, \\
x_{n+1}=\left(1-\beta_{n}\right) y_{n}+\beta_{n} T y_{n}, \quad n \geq 1 .
\end{gathered}
$$

Therein the control sequences $\left\{\alpha_{n}\right\}$ and $\left\{\beta_{n}\right\}$ satisfy certain conditions. He proved that the sequence $\left\{x_{n}\right\}$ defined by (1.3) converges strongly to $\tilde{x}=Q(f) \in \operatorname{Fix}(T)$, which is the unique solution of the variational inequality $\langle\tilde{x}-f(\tilde{x}), \tilde{x}-z\rangle \leq 0, z \in \operatorname{Fix}(T)$. The results of Jung [1] are even stronger than stated here. In fact, they hold for a finite family of nonexpansive mappings and in the setting of Banach spaces.

Very recently, Tian [2] considered the following iterative method: for nonexpansive mapping $T: H \rightarrow H$ with $\operatorname{Fix}(T) \neq \emptyset$,

$$
x_{n+1}=\alpha_{n} \gamma f\left(x_{n}\right)+\left(I-\mu \alpha_{n} F\right) T x_{n}, \quad n \geq 1,
$$

where $F$ is a $k$-Lipschitzian and $\eta$-strongly monotone operator. He obtained that the sequence $\left\{x_{n}\right\}$ generated by (1.4) converges to a point $q$ in $\operatorname{Fix}(T)$, which is the unique solution of the variational inequality $\langle(\gamma f-\mu F) q, p-q\rangle \leq 0, p \in \operatorname{Fix}(T)$.

In this connection, notice that Aoyama et al. [3] proposed a Halpern approximation method for finding a common fixed point of a countable family of nonexpansive mappings. As their main result, they established the following strong convergence theorem.

Theorem 1.1 (see [3, Theorem 3.4]). Let E be a uniformly convex Banach space whose norm is uniformly Gateaux differentiable, and let $C$ be a nonempty closed convex subset of $E$. Let $\left\{T_{n}\right\}$ be a sequence of nonexpansive mappings $T_{n}: C \rightarrow C$ such that

$$
\sum_{n=1}^{\infty} \sup \left\{\left\|T_{n+1} z-T_{n} z\right\|: z \in B\right\}<\infty
$$

for each bounded subset B of C. Suppose in addition that

$$
\operatorname{Fix}(T)=\bigcap_{n=1}^{\infty} \operatorname{Fix}\left(T_{n}\right) \neq \emptyset,
$$

where $T: C \rightarrow C$ is the nonexpansive mapping defined by $T z=\lim _{n \rightarrow \infty} T_{n} z$. Let $\alpha_{n} \in(0,1]$ be a sequence satisfying the conditions (C1) $\lim _{n \rightarrow \infty} \alpha_{n}=0$, (C2) $\sum_{n=1}^{\infty} \alpha_{n}=\infty$, and (C3) $\sum_{n=1}^{\infty} \mid \alpha_{n+1}-$ $\alpha_{n} \mid<\infty$ or $\lim _{n \rightarrow \infty}\left(\alpha_{n+1} / \alpha_{n}\right)=1$. Given $x \in C$, define $\left\{x_{n}\right\}_{n=1}^{\infty}$ by

$$
x_{1}=x, \quad x_{n+1}=\alpha_{n} x+\left(1-\alpha_{n}\right) T_{n} x_{n} .
$$

Then $\left\{x_{n}\right\}$ converges strongly to $Q x$, where $Q$ is a sunny nonexpansive retraction of $E$ onto $\operatorname{Fix}(T)$. 
Inspired by Jung [1], Tian [2] and Aoyama et al. [3], the goal of this paper is to combine these three results into a single method. In this connection, observe that the iteration methods (1.3) and (1.4) just can compute a fixed point of one nonexpansive mapping (or, perhaps, finitely many), while the iteration methods (1.3) and (1.7) do not contain the $k$-Lipschitzian and $\eta$-strongly monotone operator $F$. On the other hand, in contrast to the result of Jung [1] and Aoyama et al. [3], our result will be restricted to the setting of Hilbert spaces, which on the other hand is natural when dealing with a $k$-Lipschitzian and $\eta$-strongly monotone operator $F$.

First of all, let us remark that condition (1.5) implies that sequence of mappings $\left\{T_{n}\right\}$ are uniformly Cauchy on each bounded subset $B \subset C$. Hence the limiting map $T$ is well defined and is in fact the uniform limit (on $B$ ) of the maps $T_{n}$. In other words,

$$
\lim _{n \rightarrow \infty} \sup \left\{\left\|T z-T_{n} z\right\|: z \in B\right\}=0 .
$$

Notice that condition (1.5) is quite strong so that, in general, we cannot apply the result directly to an arbitrary countable family of nonexpansive mappings. Furthermore, we have to assume the nontrivial condition (1.6) that the fixed point set of $T$ coincides with the set of common fixed points of the family $\left\{T_{n}\right\}$.

Fortunately, as pointed out in [3, Section 4], given an arbitrary countable family of nonexpansive mappings $S_{n}: C \rightarrow C$, which have at least one common fixed point, one can find nonnegative numbers $\beta_{n}^{k}(1 \leq k \leq n, n \in \mathbb{N})$ such that the mappings

$$
T_{n} x=\sum_{k=1}^{n} \beta_{n}^{k} S_{k} x
$$

are nonexpansive self-maps of $C$ satisfying (1.5) and (1.6). More specifically, the $T_{n}$ are constructed as certain convex combinations of the $S_{1}, \ldots, S_{n}$. (For details, see the reference.) Another possibility of a construction will be mentioned below. Furthermore, we establish the following strong convergence theorem.

Theorem 1.2. Let $H$ be a real Hilbert space. Let $F$ be a $k$-Lipschitzian and $\eta$-strongly monotone operator on $H$ with $0<\mu<2 \eta / k^{2}$ and $f \in \Pi_{H}$ with $0<\gamma<\mu\left(\eta-\mu k^{2} / 2\right) / \alpha=\tau / \alpha$ and $\tau<1$. Assume that $\left\{T_{n}\right\}$ is a sequence of nonexpansive mappings from $H$ into itself such that the condition (1.5). Suppose that $T: H \rightarrow H$ is defined by $T z=\lim _{n \rightarrow \infty} T_{n} z$ such that the condition (1.6). Let $\left\{\alpha_{n}\right\},\left\{\beta_{n}\right\}$ be sequences in $(0,1)$ satisfying the following conditions:

(B1) $\lim _{n \rightarrow \infty} \alpha_{n}=0$ and $\sum_{n=1}^{\infty} \alpha_{n}=\infty$;

(B2) $b:=\limsup _{n \rightarrow \infty} \beta_{n}<1$ and $\sum_{n=1}^{\infty}\left|\beta_{n+1}-\beta_{n}\right|<\infty$;

(B3) $\left|\alpha_{n+1}-\alpha_{n}\right| \leq o\left(\alpha_{n+1}\right)+\sigma_{n}$ with $\sigma_{n} \geq 0$ and $\sum_{n=1}^{\infty} \sigma_{n}<\infty$.

Then, for arbitrary $x_{1}=x \in H$, the sequence $\left\{x_{n}\right\}_{n=1}^{\infty}$, defined by

$$
\begin{gathered}
y_{n}=\alpha_{n} \gamma f\left(x_{n}\right)+\left(I-\alpha_{n} \mu F\right) T_{n} x_{n}, \\
x_{n+1}=\left(1-\beta_{n}\right) y_{n}+\beta_{n} T_{n} y_{n}, \quad n \geq 1,
\end{gathered}
$$

converges strongly to some $q \in \operatorname{Fix}(T)$, which satisfies the variational inequality $\langle(\mu F-\gamma f) q, q-z\rangle \leq$ 0 , for all $z \in \operatorname{Fix}(T)$. 
The iterative scheme (1.10) is a direct generalization of the three iteration methods considered before. Thus Theorem 1.2 complements or improves Theorem 3.2 of Jung [1], Theorem 3.2 of Tian [2], Theorem 3.4 of Aoyama et al. [3], and Theorem 3.1 of Jung [4].

An important special case is obtained for $F=I$, the identity mapping. Then $\eta=k=1$ and we can choose $\gamma=\mu=1$ (compare with iteration scheme (1.3) above).

Besides the basic conditions (B1) and (B2) on the sequences $\alpha_{n}$ and $\beta_{n}$, we have the "control condition" (B3). It can obviously be replaced by one of the following ones:

(B3-1) $\sum_{n=1}^{\infty}\left|\alpha_{n+1}-\alpha_{n}\right|<\infty$;

(B3-2) $\alpha_{n} \in(0,1]$ for all $n \in \mathbb{N}$ and $\lim _{n \rightarrow \infty}\left(\alpha_{n+1} / \alpha_{n}\right)=1$.

Indeed, (B3-1) implies (B3) by choosing $\sigma_{n}=\left|\alpha_{n+1}-\alpha_{n}\right|$, and (B3-2) implies (B3) by choosing $\sigma_{n}=0$. In this sense, (B3) is a weaker condition than the previous condition (C3).

As has already noticed in Theorem 1.1, the assumptions (1.5) and (1.6) do not apply to arbitrary families of nonexpansive mappings. Besides the construction above, we mention another construction, which has appeared in the literature. See [5-8], the references therein, and also Remark 3.1 of Peng and Yao [9]. Proofs are given there.

Let $\left\{S_{i}: H \rightarrow H\right\}$ be a countable family of nonexpansive mappings, and let $\left\{\xi_{i}\right\}$ be a sequence of real numbers such that $0 \leq \xi_{i} \leq c<1$, for all $i \geq 1$. For any $n \geq 1$, define a mapping $T_{n}: H \rightarrow H$ as follows:

$$
\begin{aligned}
U_{n, n+1}= & I, \\
U_{n, n}= & \xi_{n} S_{n} U_{n, n+1}+\left(1-\xi_{n}\right) I, \\
U_{n, n-1}= & \xi_{n-1} S_{n-1} U_{n, n}+\left(1-\xi_{n-1}\right) I, \\
& \vdots \\
U_{n, k}= & \xi_{k} S_{k} U_{n, k+1}+\left(1-\xi_{k}\right) I, \\
& \vdots \\
U_{n, 2}= & \xi_{2} S_{2} U_{n, 3}+\left(1-\xi_{2}\right) I, \\
U_{n, 1}= & \xi_{1} S_{1} U_{n, 2}+\left(1-\xi_{1}\right) I, \\
T_{n}= & U_{n, 1} .
\end{aligned}
$$

Proposition 1.3. Let $H$ be a real Hilbert space, $\left\{S_{i}: H \rightarrow H\right\}$ a sequence nonexpansive mappings with $\bigcap_{i=1}^{\infty} \operatorname{Fix}\left(S_{i}\right) \neq \emptyset$, and $\left\{\xi_{i}\right\}$ a real sequence such that $0 \leq \xi_{i} \leq c<1$, for all $i \geq 1$. Define $\left\{T_{n}\right\}$ as above. Then

(1) $T_{n}$ is a nonexpansive and $\operatorname{Fix}\left(T_{n}\right)=\bigcap_{i=1}^{n} \operatorname{Fix}\left(S_{i}\right)$ for each $n \geq 1$;

(2) the mappings $\left\{T_{n}\right\}$ satisfy the condition (1.5);

(3) defining $T: H \rightarrow H$ by $T x=\lim _{n \rightarrow \infty} T_{n} x$, we have

$$
\operatorname{Fix}(T)=\bigcap_{n=1}^{\infty} \operatorname{Fix}\left(T_{n}\right)=\bigcap_{n=1}^{\infty} \operatorname{Fix}\left(S_{n}\right)
$$




\section{Proof of the Main Results}

Ahead of the proof, we start with recalling some known auxiliary results.

Lemma 2.1 (see [10]). Let $F$ be a $k$-Lipschitzian and $\eta$-strongly monotone operator on a Hilbert space $H$ with $k>0, \eta>0,0<\mu<2 \eta / k^{2}$, and $0<t<1$. Then $S=(I-t \mu F): H \rightarrow H$ is a contraction with contractive coefficient $1-t \tau$ and $\tau=(1 / 2) \mu\left(2 \eta-\mu k^{2}\right)$.

Lemma 2.2 (see [2]). Let $H$ be a Hilbert space. Assume that $\left\{x_{t}\right\}$ is defined by

$$
x_{t}=\operatorname{tr} f\left(x_{t}\right)+(I-t \mu F) T x_{t}
$$

where $F$ is a $k$-Lipschitzian and $\eta$-strongly monotone operator on a Hilbert space $H$ with $k>0, \eta>$ $0,0<\mu<2 \eta / k^{2}$ and $0<t<1, f \in \Pi_{H}$, and $T: H \rightarrow H$ is a nonexpansive mapping. Then $x_{t}$ converges strongly as $t \rightarrow 0$ to a fixed point $q$ of $T$, which solves the variational inequality $\langle(\mu F-$ $\gamma f) q, q-p\rangle \leq 0, p \in F(T)$.

Some more auxiliary results are given next.

Lemma 2.3 (see [11]). Let $H$ be a Hilbert space, $C$ a closed convex subset of $H$, and $T: C \rightarrow C$ a nonexpansive mapping with $\operatorname{Fix}(T) \neq \emptyset$. If $\left\{x_{n}\right\}$ is a sequence in $C$ which converges weakly to $x$ and if $\left\{(I-T) x_{n}\right\}$ converges strongly to $y$, then $(I-T) x=y$.

Lemma 2.4 (see [3, Lemma 2.3]). Let $\left\{s_{n}\right\}$ be a sequence of nonnegative real numbers, $\left\{\delta_{n}\right\}$ a sequence of numbers in $[0,1]$ such that $\sum_{n=1}^{\infty} \delta_{n}=\infty,\left\{\mu_{n}\right\}$ a sequence of nonnegative real numbers with $\sum_{n=1}^{\infty} \mu_{n}<\infty$, and $\left\{\theta_{n}\right\}$ a sequence of real numbers with $\lim _{\sup } \operatorname{pof}_{n \rightarrow \infty} \theta_{n} \leq 0$. Suppose that

$$
s_{n+1} \leq\left(1-\delta_{n}\right) s_{n}+\delta_{n} \theta_{n}+\mu_{n}
$$

for all $n \in \mathbb{N}$. Then $\lim _{n \rightarrow \infty} s_{n}=0$.

Now we are prepared to prove the main result.

Proof of Theorem 1.2. We divide the proof into seven steps.

Step 1 . We claim that $\left\{x_{n}\right\}$ is bounded. Taking any point $q \in \bigcap_{n=1}^{\infty} \operatorname{Fix}\left(T_{n}\right)$ and using Lemma 2.1, we obtain

$$
\begin{aligned}
\left\|x_{n+1}-q\right\| & =\left\|\left(1-\beta_{n}\right)\left(y_{n}-q\right)+\beta_{n}\left(T_{n} y_{n}-q\right)\right\| \\
& \leq\left\|y_{n}-q\right\| \\
& =\left\|\alpha_{n}\left(\gamma f\left(x_{n}\right)-\mu F q\right)+\left(I-\alpha_{n} \mu F\right) T_{n} x_{n}-\left(I-\alpha_{n} \mu F\right) q\right\| \\
& \leq\left(1-\alpha_{n} \tau\right)\left\|x_{n}-q\right\|+\alpha_{n}\left\|\gamma f\left(x_{n}\right)-\mu F q\right\| \\
& \leq\left(1-\alpha_{n} \tau\right)\left\|x_{n}-q\right\|+\alpha_{n}\left\|\gamma f\left(x_{n}\right)-\gamma f(q)\right\|+\alpha_{n}\|\gamma f(q)-\mu F q\| \\
& \leq\left(1-\alpha_{n} \tau\right)\left\|x_{n}-q\right\|+\alpha_{n} \gamma \alpha\left\|x_{n}-q\right\|+\alpha_{n}\|\gamma f(q)-\mu F q\|
\end{aligned}
$$




$$
\begin{aligned}
& \leq\left(1-\alpha_{n}(\tau-\gamma \alpha)\right)\left\|x_{n}-q\right\|+\alpha_{n}(\tau-\gamma \alpha) \frac{\|\gamma f(q)-\mu F q\|}{\tau-\gamma \alpha} \\
& \leq \max \left\{\left\|x_{n}-q\right\|, \frac{\|\gamma f(q)-\mu F q\|}{\tau-\gamma \alpha}\right\} .
\end{aligned}
$$

By induction, it follows

$$
\left\|x_{n}-q\right\| \leq \max \left\{\left\|x_{1}-q\right\|, \frac{\|\gamma f(q)-\mu F q\|}{\tau-\gamma \alpha}\right\}, \quad n \geq 1
$$

and hence $\left\{x_{n}\right\}$ is bounded. From this, we also obtain that $\left\{y_{n}\right\},\left\{T_{n} y_{n}\right\},\left\{F T_{n} x_{n}\right\}$, and $\left\{f\left(x_{n}\right)\right\}$ are all bounded. In what follows, let $B$ stand for some bounded set of $H$, which contains all of $\left\{x_{n}\right\},\left\{y_{n}\right\},\left\{T_{n} y_{n}\right\},\left\{F T_{n} x_{n}\right\},\left\{f\left(x_{n}\right)\right\}$.

Step 2. We show that $\lim _{n \rightarrow \infty}\left\|x_{n+1}-x_{n}\right\|=0$. we obtain

Let $M=\sup \left\{\left\|T_{n} y_{n}-y_{n}\right\|,\left\|f\left(x_{n}\right)\right\|,\left\|F T_{n} x_{n}\right\|: n \in \mathbb{N}\right\}<\infty$. From the definition of $\left\{x_{n}\right\}$,

$$
\begin{aligned}
\left\|x_{n+2}-x_{n+1}\right\|= & \left\|\left(1-\beta_{n+1}\right) y_{n+1}+\beta_{n+1} T_{n+1} y_{n+1}-\left(1-\beta_{n}\right) y_{n}-\beta_{n} T_{n} y_{n}\right\| \\
= & \|\left(1-\beta_{n+1}\right) y_{n+1}+\beta_{n+1} T_{n+1} y_{n+1}-\left(1-\beta_{n+1}\right) y_{n}-\left(\beta_{n+1}-\beta_{n}\right) y_{n} \\
& \quad-\beta_{n+1} T_{n} y_{n}+\left(\beta_{n+1}-\beta_{n}\right) T_{n} y_{n} \| \\
= & \left\|\left(1-\beta_{n+1}\right)\left(y_{n+1}-y_{n}\right)+\beta_{n+1}\left(T_{n+1} y_{n+1}-T_{n} y_{n}\right)+\left(\beta_{n+1}-\beta_{n}\right)\left(T_{n} y_{n}-y_{n}\right)\right\| \\
\leq & \left(1-\beta_{n+1}\right)\left\|y_{n+1}-y_{n}\right\|+\beta_{n+1}\left\|T_{n+1} y_{n+1}-T_{n} y_{n}\right\|+\left|\beta_{n+1}-\beta_{n}\right| M \\
\leq & \left(1-\beta_{n+1}\right)\left\|y_{n+1}-y_{n}\right\|+\beta_{n+1}\left\|T_{n+1} y_{n+1}-T_{n} y_{n+1}\right\|+\beta_{n+1}\left\|y_{n+1}-y_{n}\right\| \\
& \quad+\left|\beta_{n+1}-\beta_{n}\right| M \\
\leq & \left\|y_{n+1}-y_{n}\right\|+\left\|T_{n+1} y_{n+1}-T_{n} y_{n+1}\right\|+\left|\beta_{n+1}-\beta_{n}\right| M
\end{aligned}
$$

for all $n \in \mathbb{N}$. From (1.10), we have

$$
\begin{gathered}
y_{n}=\alpha_{n} \gamma f\left(x_{n}\right)+\left(I-\alpha_{n} \mu F\right) T_{n} x_{n}, \\
y_{n+1}=\alpha_{n+1} \gamma f\left(x_{n+1}\right)+\left(I-\alpha_{n+1} \mu F\right) T_{n+1} x_{n+1} .
\end{gathered}
$$


With $M_{1}=(\mu+\gamma) M$, we thus have

$$
\begin{aligned}
\left\|y_{n+1}-y_{n}\right\|= & \left\|\alpha_{n+1} \gamma f\left(x_{n+1}\right)+\left(I-\alpha_{n+1} \mu F\right) T_{n+1} x_{n+1}-\alpha_{n} \gamma f\left(x_{n}\right)-\left(I-\alpha_{n} \mu F\right) T_{n} x_{n}\right\| \\
= & \|\left(I-\alpha_{n+1} \mu F\right) T_{n+1} x_{n+1}-\left(I-\alpha_{n+1} \mu F\right) T_{n} x_{n}-\left(\alpha_{n+1}-\alpha_{n}\right) \mu F T_{n} x_{n} \\
& \quad+\alpha_{n+1} \gamma\left(f\left(x_{n+1}\right)-f\left(x_{n}\right)\right)+\left(\alpha_{n+1}-\alpha_{n}\right) \gamma f\left(x_{n}\right) \| \\
\leq & \left(1-\alpha_{n+1} \tau\right)\left\|T_{n+1} x_{n+1}-T_{n} x_{n}\right\|+\left|\alpha_{n+1}-\alpha_{n}\right| \mu\left\|F T_{n} x_{n}\right\|+\alpha_{n+1} \gamma \alpha\left\|x_{n+1}-x_{n}\right\| \\
& \quad+\gamma\left|\alpha_{n+1}-\alpha_{n}\right|\left\|f\left(x_{n}\right)\right\| \\
\leq & \left(1-\alpha_{n+1} \tau\right)\left\|T_{n+1} x_{n+1}-T_{n} x_{n}\right\|+\alpha_{n+1} \gamma \alpha\left\|x_{n+1}-x_{n}\right\|+\left|\alpha_{n+1}-\alpha_{n}\right| M_{1} \\
\leq & \left(1-\alpha_{n+1} \tau\right)\left(\left\|T_{n+1} x_{n+1}-T_{n+1} x_{n}\right\|+\left\|T_{n+1} x_{n}-T_{n} x_{n}\right\|\right)+\alpha_{n+1} \gamma \alpha\left\|x_{n+1}-x_{n}\right\| \\
& +M_{1}\left|\alpha_{n+1}-\alpha_{n}\right| \\
\leq & {\left[1-\alpha_{n+1}(\tau-\gamma \alpha)\right]\left\|x_{n+1}-x_{n}\right\|+\left\|T_{n+1} x_{n}-T_{n} x_{n}\right\|+M_{1}\left|\alpha_{n+1}-\alpha_{n}\right| . }
\end{aligned}
$$

Combining (2.5) and (2.7), we conclude that

$$
\begin{aligned}
\left\|x_{n+2}-x_{n+1}\right\| \leq & {\left[1-\alpha_{n+1}(\tau-\gamma \alpha)\right]\left\|x_{n+1}-x_{n}\right\|+M_{2}\left(\left|\alpha_{n+1}-\alpha_{n}\right|+\left|\beta_{n+1}-\beta_{n}\right|\right) } \\
& +2 \sup \left\{\left\|T_{n+1} z-T_{n} z\right\|: z \in B\right\}
\end{aligned}
$$

where $M_{2}=\max \left\{M, M_{1}\right\}$. Using the assumption (B3), we obtain

$$
\left\|x_{n+2}-x_{n+1}\right\| \leq\left[1-\alpha_{n+1}(\tau-\gamma \alpha)\right]\left\|x_{n+1}-x_{n}\right\|+M_{2} o\left(\alpha_{n+1}\right)+\mu_{n}
$$

with $\mu_{n}=M_{2}\left(\sigma_{n}+\left|\beta_{n+1}-\beta_{n}\right|\right)+2 \sup \left\{\left\|T_{n+1} z-T_{n} z\right\|: z \in B\right\}$. The various assumptions imply that $\sum_{n=1}^{\infty} \mu_{n}<\infty$. Now it follows from Lemma 2.4 that $\lim _{n \rightarrow \infty}\left\|x_{n+1}-x_{n}\right\|=0$.

Step 3. Next we show that

$$
\lim _{n \rightarrow \infty}\left\|T_{n} x_{n}-y_{n}\right\|=\lim _{n \rightarrow \infty}\left\|x_{n}-y_{n}\right\|=0
$$

In fact, from Step 1, $\left\{\gamma f\left(x_{n}\right)-\mu F T_{n} x_{n}\right\}$ is bounded. Moreover, it follows from $\lim _{n \rightarrow \infty} \alpha_{n}=0$ that

$$
\left\|T_{n} x_{n}-y_{n}\right\|=\left\|\alpha_{n} \gamma f\left(x_{n}\right)-\alpha_{n} \mu F T_{n} x_{n}\right\|=\alpha_{n}\left\|\gamma f\left(x_{n}\right)-\mu F T_{n} x_{n}\right\| \longrightarrow 0 \quad(n \longrightarrow \infty)
$$

This is the first part. From condition (B2), we obtain, for $n$ sufficiently large and $b<b_{1}<1$,

$$
\begin{aligned}
\left\|x_{n+1}-y_{n}\right\| & =\beta_{n}\left\|T_{n} y_{n}-y_{n}\right\| \\
& \leq \beta_{n}\left(\left\|T_{n} y_{n}-T_{n} x_{n}\right\|+\left\|T_{n} x_{n}-y_{n}\right\|\right) \\
& \leq b_{1}\left(\left\|y_{n}-x_{n}\right\|+\left\|T_{n} x_{n}-y_{n}\right\|\right) \\
& \leq b_{1}\left(\left\|y_{n}-x_{n+1}\right\|+\left\|x_{n+1}-x_{n}\right\|+\left\|T_{n} x_{n}-y_{n}\right\|\right),
\end{aligned}
$$


which implies

$$
\left\|x_{n+1}-y_{n}\right\| \leq \frac{b_{1}}{1-b_{1}}\left(\left\|x_{n+1}-x_{n}\right\|+\left\|T_{n} x_{n}-y_{n}\right\|\right)
$$

Hence, using Step 2 and the above, we obtain $\lim _{n \rightarrow \infty}\left\|x_{n+1}-y_{n}\right\|=0$ and thus $\lim _{n \rightarrow \infty} \| x_{n}-$ $y_{n} \|=0$.

Step 4 . We show that $\lim _{n \rightarrow \infty}\left\|y_{n}-T_{n} y_{n}\right\|=0$.

Indeed, we have

$$
\begin{aligned}
\left\|y_{n}-T_{n} y_{n}\right\| & \leq\left\|y_{n}-T_{n} x_{n}\right\|+\left\|T_{n} x_{n}-T_{n} y_{n}\right\| \\
& \leq\left\|y_{n}-T_{n} x_{n}\right\|+\left\|x_{n}-y_{n}\right\|,
\end{aligned}
$$

and now the statement follows from Step 3.

Step 5 . We show that $\left\|T y_{n}-y_{n}\right\| \rightarrow 0$ as $n \rightarrow \infty$.

Observe that

$$
\begin{aligned}
\left\|T y_{n}-y_{n}\right\| & \leq\left\|T y_{n}-T_{n} y_{n}\right\|+\left\|T_{n} y_{n}-y_{n}\right\| \\
& \leq \sup \left\{\left\|T z-T_{n} z\right\|: z \in B\right\}+\left\|T_{n} y_{n}-y_{n}\right\|
\end{aligned}
$$

and now apply Step 4 and the fact that $T_{n}$ converges uniformly on $B$ to $T$ (which is a consequence of (1.5)).

Step 6. We claim that $\lim \sup _{n \rightarrow \infty}\left\langle\gamma f(q)-\mu F q, y_{n}-q\right\rangle \leq 0$, where $q=\lim _{t \rightarrow 0} x_{t}$ with $x_{t}$ defined by (2.1) and the existence of $q$ being guaranteed by Lemma 2.2.

Assume the contrary. Then there exists a subsequence $\left\{y_{n_{k}}\right\}$ of $\left\{y_{n}\right\}$ such that the limit

$$
c:=\lim _{k \rightarrow \infty}\left\langle\gamma f(q)-\mu F q, y_{n_{k}}-q\right\rangle
$$

exists and is greater than zero. Since $\left\{y_{n}\right\}$ is bounded, there exists a subsequence of $\left\{y_{n_{k}}\right\}$, which converges weakly to some $z \in H$. We can assume without loss of generality that $\left\{y_{n_{k}}\right\}$ is this subsequence. From $\left\|T y_{n}-y_{n}\right\| \rightarrow 0$, we obtain that $T y_{n_{k}}$ converges weakly to $z$. Now Lemma 2.3 implies that $z \in \operatorname{Fix}(T)$. Hence from weak convergence and Lemma 2.2,

$$
\lim _{k \rightarrow \infty}\left\langle\gamma f(q)-\mu F q, y_{n_{k}}-q\right\rangle=\langle(\gamma f-\mu F) q, z-q\rangle \leq 0
$$

This is a contradiction.

Step 7 . We show that $\left\{x_{n}\right\}$ converges strongly to $q$. From (1.10), we have

$$
\begin{aligned}
\left\|x_{n+1}-q\right\|^{2} & =\left\|\left(1-\beta_{n}\right)\left(y_{n}-q\right)+\beta_{n}\left(T_{n} y_{n}-q\right)\right\|^{2} \\
& \leq\left\|y_{n}-q\right\|^{2} \\
& =\left\|\alpha_{n} \gamma f\left(x_{n}\right)+\left(I-\alpha_{n} \mu F\right) T_{n} x_{n}-q\right\|^{2} \\
& =\left\|\alpha_{n}\left(\gamma f\left(x_{n}\right)-\mu F q\right)+\left(I-\alpha_{n} \mu F\right) T_{n} x_{n}-\left(I-\alpha_{n} \mu F\right) q\right\|^{2} .
\end{aligned}
$$


Using the general inequality $\|x+y\|^{2} \leq\|x\|^{2}+2\langle y, x+y\rangle$, we can further estimate the above by

$$
\begin{aligned}
\leq & \left\|\left(I-\alpha_{n} \mu F\right) T_{n} x_{n}-\left(I-\alpha_{n} \mu F\right) q\right\|^{2}+2 \alpha_{n}\left\langle\gamma f\left(x_{n}\right)-\mu F q, y_{n}-q\right\rangle \\
\leq & \left(1-\alpha_{n} \tau\right)^{2}\left\|x_{n}-q\right\|^{2}+2 \alpha_{n}\left\langle\gamma f\left(x_{n}\right)-\gamma f(q), y_{n}-q\right\rangle+2 \alpha_{n}\left\langle\gamma f(q)-\mu F q, y_{n}-q\right\rangle \\
\leq & \left(1-\alpha_{n} \tau\right)^{2}\left\|x_{n}-q\right\|^{2}+2 \alpha_{n} \gamma \alpha\left\|x_{n}-q\right\|\left(\left\|y_{n}-x_{n}\right\|+\left\|x_{n}-q\right\|\right)+2 \alpha_{n}\left\langle\gamma f(q)-\mu F q, y_{n}-q\right\rangle \\
\leq & \left(1-2 \alpha_{n}(\tau-\gamma \alpha)\right)\left\|x_{n}-q\right\|^{2}+\left(\alpha_{n} \tau\right)^{2}\left\|x_{n}-q\right\|^{2}+2 \alpha_{n} \gamma \alpha\left\|x_{n}-q\right\|\left\|y_{n}-x_{n}\right\| \\
& +2 \alpha_{n}\left\langle\gamma f(q)-\mu F q, y_{n}-q\right\rangle .
\end{aligned}
$$

Introducing $M_{3}=\sup \left\{\left\|x_{n}-q\right\|: n \geq 1\right\}, \delta_{n}=2 \alpha_{n}(\tau-\gamma \alpha)>0$, and

$$
\theta_{n}=\frac{\alpha_{n} \tau^{2} M_{3}^{2}}{2(\tau-\gamma \alpha)}+\frac{\gamma \alpha M_{3}}{\tau-\gamma \alpha}\left\|y_{n}-x_{n}\right\|+\frac{1}{\tau-\gamma \alpha}\left\langle\gamma f(q)-\mu F q, y_{n}-q\right\rangle
$$

we obtain

$$
\left\|x_{n+1}-q\right\|^{2} \leq\left(1-\delta_{n}\right)\left\|x_{n}-q\right\|^{2}+\delta_{n} \theta_{n} .
$$

Because $\delta_{n} \rightarrow 0, \sum_{n=1}^{\infty} \delta_{n}=\infty$, and $\limsup _{n \rightarrow \infty} \theta_{n} \leq 0$, it follows from Lemma 2.4 that the sequence $\left\{x_{n}\right\}$ converges strongly to $q$. This finishes the proof of the main part of the theorem.

From the definition of $q$ as $q=\lim _{t \rightarrow 0} x_{t}$ (see Step 6) and from Lemma 2.2, we obtain $\langle(\mu F-\gamma f) q, q-z\rangle \leq 0$, for all $z \in \operatorname{Fix}(T)=\bigcap_{n=1}^{\infty} \operatorname{Fix}\left(T_{n}\right)$. This completes the proof.

\section{Acknowledgment}

This author is supported by the Natural Science Foundation of Yancheng Teachers University under Grant (11YCKL009).

\section{References}

[1] J. S. Jung, "Convergence on composite iterative schemes for nonexpansive mappings in Banach spaces," Fixed Point Theory and Applications, vol. 2008, Article ID 167535, 14 pages, 2008.

[2] M. Tian, "A general iterative algorithm for nonexpansive mappings in Hilbert spaces," Nonlinear Analysis. Theory, Methods \& Applications, vol. 73, no. 3, pp. 689-694, 2010.

[3] K. Aoyama, Y. Kimura, W. Takahashi, and M. Toyoda, "Approximation of common fixed points of a countable family of nonexpansive mappings in a Banach space," Nonlinear Analysis. Theory, Methods E Applications, vol. 67, no. 8, pp. 2350-2360, 2007.

[4] J. S. Jung, "Strong convergence of composite iterative methods for nonexpansive mappings," Journal of the Korean Mathematical Society, vol. 46, no. 6, pp. 1151-1164, 2009.

[5] W. Takahashi and K. Shimoji, "Convergence theorems for nonexpansive mappings and feasibility problems," Mathematical and Computer Modelling, vol. 32, no. 11-13, pp. 1463-1471, 2000.

[6] K. Shimoji and W. Takahashi, "Strong convergence to common fixed points of infinite nonexpansive mappings and applications," Taiwanese Journal of Mathematics, vol. 5, no. 2, pp. 387-404, 2001. 
[7] S.-S. Chang, H. W. Joseph Lee, and C. K. Chan, "A new method for solving equilibrium problem fixed point problem and variational inequality problem with application to optimization," Nonlinear Analysis. Theory, Methods E Applications, vol. 70, no. 9, pp. 3307-3319, 2009.

[8] Y. H. Yao, Y.-C. Liou, and J.-C. Yao, "Convergence theorem for equilibrium problems and fixed point problems of infinite family of nonexpansive mappings," Fixed Point Theory and Applications, vol. 2007, Article ID 64363, 12 pages, 2007.

[9] J.-W. Peng and J.-C. Yao, "A viscosity approximation scheme for system of equilibrium problems, nonexpansive mappings and monotone mappings," Nonlinear Analysis. Theory, Methods E Applications, vol. 71, no. 12, pp. 6001-6010, 2009.

[10] S. Wang, "A general iterative method for obtaining an infinite family of strictly pseudo-contractive mappings in Hilbert spaces," Applied Mathematics Letters, vol. 24, no. 6, pp. 901-907, 2011.

[11] K. Goebel and W. A. Kirk, Topics in Metric Fixed Point Theory, Cambridge Studies in Advanced Mathematics, vol. 28, Cambridge University Press, Cambridge, UK, 1990. 


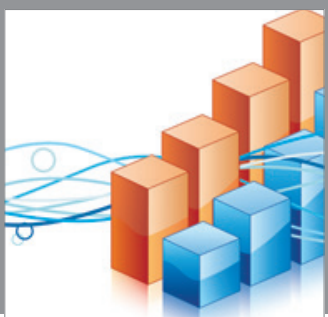

Advances in

Operations Research

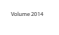

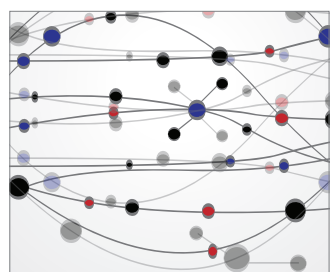

\section{The Scientific} World Journal
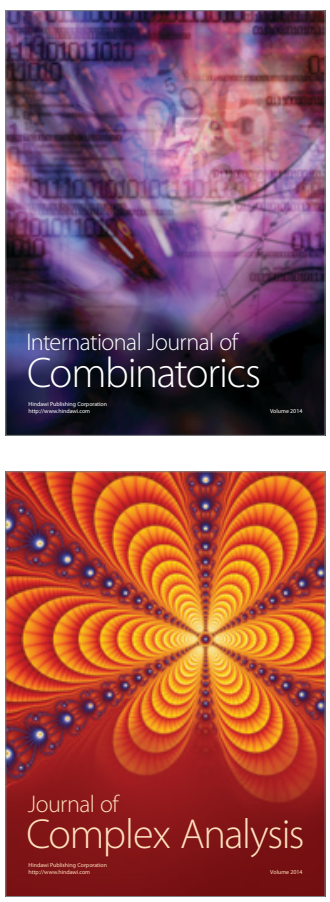

International Journal of

Mathematics and

Mathematical

Sciences
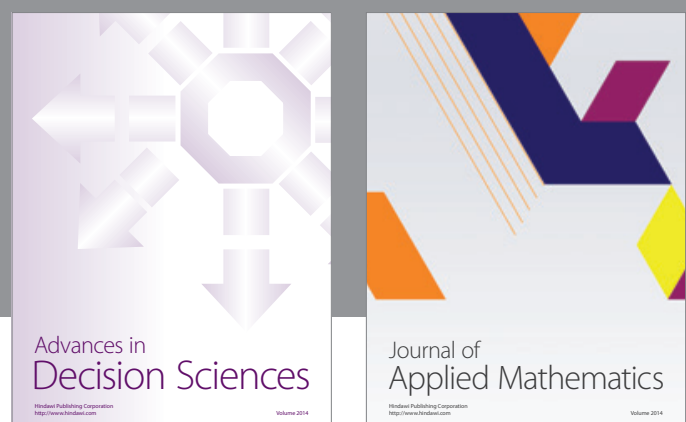

Journal of

Applied Mathematics
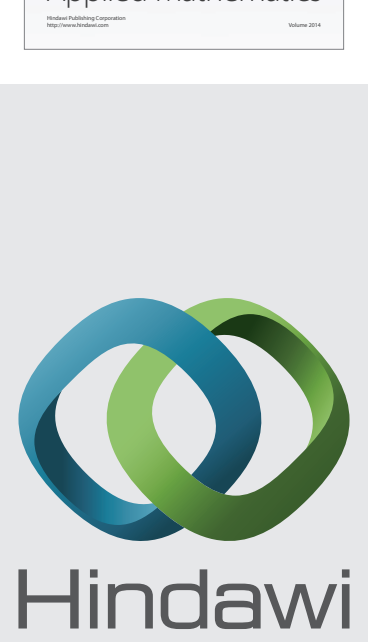

Submit your manuscripts at http://www.hindawi.com
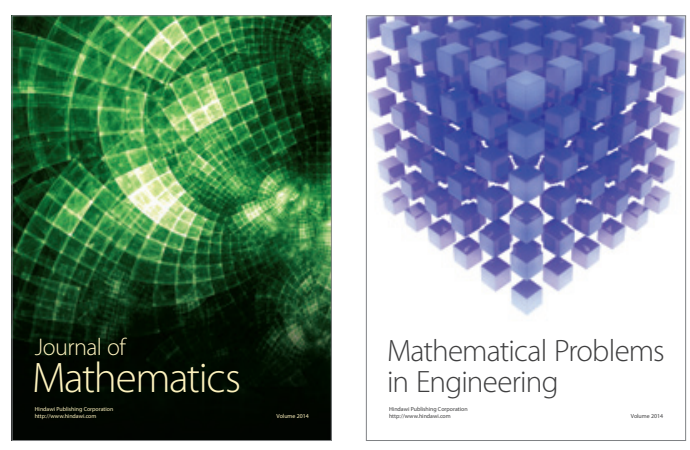

Mathematical Problems in Engineering
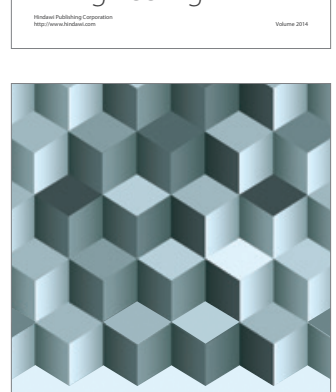

Journal of

Function Spaces
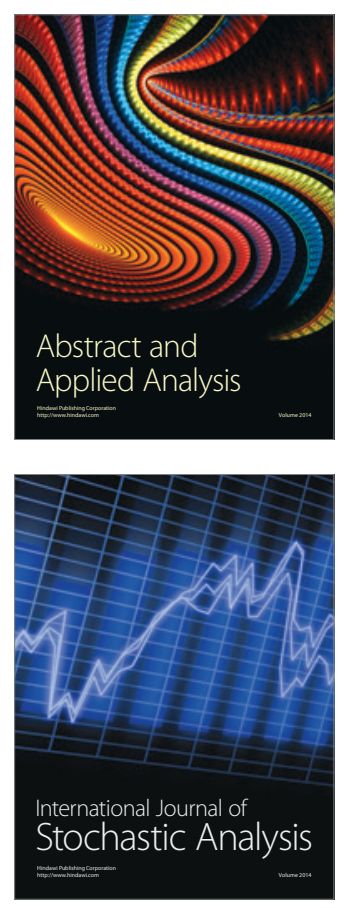

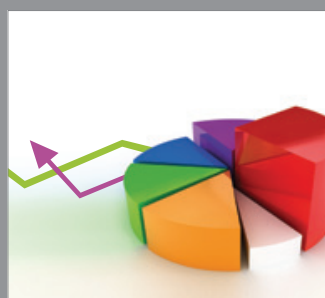

ournal of

Probability and Statistics

Promensencen
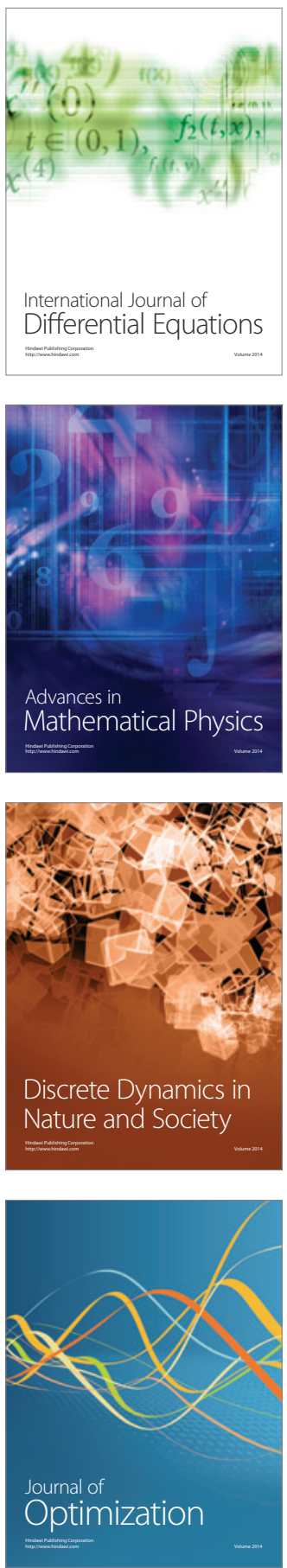